\title{
VARIA
}

\section{EL TAPIZ, ESPEJO DE LA AVENTURA: SU REFLEJO AMERICANO *}

En el ámbito europeo de la Edad Media hubo un medio de expresión plástica que, junto a la literatura, supo ser el espejo en el cual nobles y pecheros vieron reflejada la imagen, más querida que real, de una sociedad regida por los ideales de la caballería.

Los paladines, defensores del honor, de los oprimidos, de las causas justas, cantados por los trovadores hasta en los más recónditos rincones, eran retratados en sus hazañas por medio de los hilos de colores urdidos en los telares de tapicería. Sus gestas tejidas se convertían en ilustraciones que completaban lo que el juglar o el trovador cantaban en sus versos.

Pero los liceros no sólo reflejaron gestas heroicas antiguas o modernas sino que también se ocuparon de la vida de las cortes, de sus diversiones y cacerías, de los sueños y fantasías de damas y caballeros, de tierras lejanas, exóticas y desconocidas pobladas por extraños seres. Príamo y Héctor, Paris y Elena, Alejandro y Diocleciano, Carlomagno y los Doce Pares; caballeros con halcones en sus manos, damas en sus jardines secretos; naos que surcan la mar, salvajes y leones, centauros y dromedarios... llenaron los muros de los castillos de personajes variopintos que evolucionaban en un mundo irreal lleno de anacronismos y de licencias geográficas. Constituían así un verdadero espejo moral donde el futuro caballero aprendía - como, otros, en la Biblia Pauperum - las virtudes y las reglas, los deseos, de su grupo social.

Esto hizo del tapiz una manifestación plástica llena de expresividad que, con frecuencia, explicaba por medio de unas cartelas su contenido. Se convirtió de este modo en muestra palpable y evidente de la categoría social de su dueño, dando origen a una industria que fue causa de la prosperidad económica de una región europea, Flandes, la cual habría de integrarse en la monarquía hispánica como consecuencia de la política económica de Castilla ${ }^{1}$.

El comercio lanero de la Península Ibérica con los territorios del Duque de Borgoña, confirmó el gusto español por la tapicería de tal modo que, en los albores del siglo xvi, la cantidad de «paños de ras» llegados a Aragón y Castilla fue enorme, consolidándose un proceso que iría en progresión hasta el reinado de Felipe V.

\footnotetext{
* Texto revisado de la comunicación presentada en Querétaro en 1990 en el Congreso, 1492: Encuentro entre dos mundos.

' Valentín VÁzquez de PRAda: Les relations commerciales hispanoflamandes et l'importation de tapisseries en Espagne, Catálogo «uropalia $85 "$ ", Bruselas.
} 
De este mundo caballeresco es de donde saldrán los impulsos que harán posible el descubrimiento de América, hecho cuyos preparativos se enmarcan entre tapices puesto que la reina Isabel fue una de las más importantes coleccionistas de su tiempo ${ }^{2}$ y Don Fernando recibía a sus visitantes en su tienda de Santa Fe rodeado de tapicerías ${ }^{3}$.

La colección de la reina, que constaba de más de trescientas setenta piezas, es el perfecto ejemplo del gusto del estamento aristocrático, imbuido de ideales caballerescos, de amor cortés.

Los temas representados abarcaban desde lo religioso - Antiguo y Nuevo Testamento, temas teológicos, vidas de santos- a las alegorías y moralidades, pasando por la mitología, la historia antigua, las escenas de corte y, como era de esperar, los temas artúricos o la Historia de Oriande, versión probable de un Amadís ${ }^{4}$; no faltando, tampoco, los temas exótico-fantásticos de los boscajes con leones y unicornios.

Parecidos temas volvemos a encontrar en la colección del Duque de Calabria, heredero del rey de Nápoles, quien tenía una serie de tapices con la historia de «La Cristina», sin duda tomada de «La Ciudad de las Damas» de Christine de Pisan ${ }^{5}$, y once paños «de Tornay de Indios», seguramente de los salidos de los telares de Jean y Antoine Grenier y Arnould Poissonnier, que conocemos bajo los apelativos de tapices «a la manière de Portugal et de Indie» (1504), de «la caravana» (1508), de «histoire de gens et de bêtes sauvages à la manière de Calcou» (1510), el «voyage de Caluce» (1513), la «histoire de Calcou» (1522), la «histoire de la Caravanne» (1522), semejantes a la serie desaparecida que Pierre van Aelst vendió en 1522 a Carlos I, constituida por seis tapices de «l'histoire indienne à oliffans et jeraffes» ${ }^{6}$.

$\mathrm{Y}$ es en estas series narradoras de viajes y expediciones a lejanos y desconocidos países donde vemos cómo el espíritu medieval, que había desarrollado mundos fantásticos poblados de extraños seres, se encuentra con las noticias venidas de esa América que aún no se llama así, y en las que realidad y ficción, lo anhelado y temido se enfrentan a lo visto y ya presentido en la conquista de Canarias concluida en $1496^{7}$.

Las Canarias y sus gentes deben ser las que aparecen en un paño de Tournai, tejido por cartón de Alonso Cebadero y testimonio temprano de ese afán de reflejar los hechos históricos, las hazañas, realizados por navegantes y conquistadores españoles.

En el tapiz vemos a un jefe guanche (?) entronizado y bajo un dosel rodeado por músicos y guerreros. Estos son blancos y negros pero, todos, de pelo corto y crespo lo cual, unido a la gran estatura de un personaje maniatado que aparece en primer término, parece abonar la idea de su origen étnico no americano. En el ángulo izquierdo, bajo un cartel que dice «Cevadero pintor» éste, sentado en un jamuga, dibuja sobre una mesa.

\footnotetext{
${ }^{2}$ Francisco Javier Sánchez Cantón: Libros, Tapices y Cuadros que coleccionó Isabel la Católica, Madrid, 1950. Antonio de la Torre y del Cerro: Testamentaría de Isabel la Católica, Barcelona, 1974

${ }^{3}$ Alonso de Santa Cruz: Crónica de los Reyes Católicos, ed. de Juan de Mata Carriazo, Sevilla, 1951, vol. I, pág. 35.

4 Véase Betty Kurth: «Medieval Romances in Renaissance Tapestries», en Journal of the Warburg and Courtauld Institutes, vol. V, 1942, págs. 237-245.

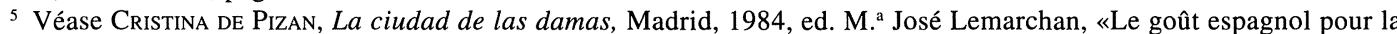
tapisserie», en el Catálogo Tapisserie de Tournai en Espagne-La Tapisserie bruxelloise en Espagne au XVIe siècle», Europalia 85, España- Bruselas, 1985, pág. 27. Aparece citado -por error del transcriptor belga- como «La Celestina».

${ }^{6}$ Véase un resumen de la cuestión en J.P. Asselberghs: La tapisserie tournaisienne du XVIe siècle, Tournai, 1968, págs. 12-16 y J.J. Junquera, op. cit., págs. 158-159.

7 Véase Timothy Husband y Gloria Gilmore-House: The Wild Man. Medieval Myth and Symbolism, Nueva York, The Metropolitan Museum of Art, 1980, y muy especialmente el capítulo «La perspectiva», Luis WeCKMANN: La herencia medieval de México, México, 1984, vol. I, págs. 19 y sigs.; Ida Rodríguez Prampolini: Amadises de América. La hazaña de Indias como empresa caballeresca, México, 1948; Irving A. LeOnARD: Los libros del conquistador, $2^{\text {a }}$ ed. española, México, 1979; Jorge Alberto Manrique: «Ambigüedad histórica del arte mexicano», en Del Arte. Homenaje a Justino Fernández, México, 1977.
} 
Pero no es esto todo lo que podemos ver en el tapiz ya que, además, hay desnudos femeninos, tupida vegetación entre la cual destaca un drago junto al dosel real; un papagayo, un mono, una lechuza, una ardilla y un gato componen la extraña fauna culminada por un cuadrúpedo de rostro humano al que cabalga un músico que, quizás, represente a Nabucodonosor. Al fondo, un amplio paisaje con pintorescas construcciones entre las que desarrollan sus actividades personajes de raza negra, agricultores y pastores de vacas.

La mezcla de animales europeos, africanos y fantásticos, muestra la unión de fantasía y realidad, el manejo de fuentes grabadas y relatos de marinos que han llegado, desde el suroeste peninsular, a las costas de Guinea.

En cuanto a los grabados, no queda duda de su origen flamenco. Tanto las construcciones como la lechuza o el drago traen a la memoria la obra del Bosco; y en el tapiz, como en los cuadros del Maestro de Hertogenbosch, serán testimonio de un lenguaje simbólico ${ }^{8}$.

Con estas breves pinceladas podemos hacernos una idea de cómo el tapiz reflejaba la mentalidad de las clases altas españolas coetáneas de la Conquista, y de su importancia como testimonio de la posición social de sus dueños.

Parecido debió ser lo sucedido en el México de Cortés y en el Perú de Pizarro si nos atenemos a algunos testimonios, de muy diverso orden, aún existentes.

En primer lugar, el inventario de las tapicerías que poseyó el propio Marqués del Valle de Oaxaca en su palacio de Cuernavaca ${ }^{9}$.

Como es bien sabido, el extremeño constituye un claro exponente de los vicios y virtudes de su época. Gracias a los testimonios de sus contemporáneos conocemos bien los rasgos que le religan al mundo crepuscular de la caballería, desde su gusto por la cetrería a sus citas de hechos y dichos de caballeros librescos, a su manera de mirar gentes, paisajes y ciudades con los ojos de un caballero andante escapado de una página del Amadís.

Por ello, como era lógico, su casa se adornaba con tapices cuyos temas no hubieran sido diferentes en el palacio de un Mendoza o de un Toledo, acá, en la lejana Castilla, y cuyo número no era, ni mucho menos, despreciable.

Entre los veintisiete paños enumerados en el inventario, podemos deducir el asunto de algunos a pesar de lo somero de su descripción. Los hay con temas que proceden de textos literarios enmarcados en el llamado amor cortés, y a los cuales el redactor del inventario llama «paños de corte»: «Primeramente un paño de corte, tapiz de figuras, demediado, que tuvo seis varas de largo e tres varas de ancho, con un elefante e otras figuras»; género al que parecen pertenecer los cinco siguientes. A continuación de ellos aparece la siguiente pieza: «Item otro paño de figuras demediado e sin seda e con tres figuras de elefantes, que tuvo tres varas e cuarto de caída, e de ancho cinco varas e una cuarta escasas e cuatro varas de ancho».

De nuevo hay elefantes en el paño citado en el lugar vigesimoprimero: «Item otro paño tapiz, demediado, de figuras o arboleda con dos elefantes, sin seda, que tuvo de caída tres varas, e de ancho tres varas e media».

Tanto este último tapiz como el anterior podrían formar parte de una serie como las tejidas en Tournai con temas exóticos, mientras que en el denominado «paño de corte», quizás el pro-

\footnotetext{
${ }^{8}$ El tapiz, al parecer en una colección privada suiza, fue publicado como de tema «indio»: MADELEINE JARRY: L'Homme Sauvage, «L'OEIL», N 183, marzo 1970, págs. 14-21. Sobre el drago véase: Isabel Mateo Gómez: Traza y Baza, nº 1 , pp. 9-18.

${ }^{9}$ Postrera voluntad y testamento de Hernando Cortés, Marqués del Valle. Introducción y notas de G. R.G. Conway, México, 1940; M. Toussaint, «el criterio artístico de Hernán Cortés», Estudios Americanos, I.I.E., México, XV, 1947; M. Hernández SÁnchez-Barba: Cartas y documentos de Hernán Cortes; Federico Gómez de Orozco: El mobiliario y la decoración en la Nueva España en el siblo XVI, México, 1983, de donde, numerándolo, tomo el inventario.
} 
boscídeo hiciera alusión a la piedad y la castidad, virtudes que los antiguos - Aristóteles y Plinio, entre otros- atribuían a estas bestias como luego haría Justus Lipsius ${ }^{10}$. Los asuntos exóticos a los ojos europeos siguen en los paños que, como el decimoctavo, tienen enmedio «una jaula e dos papagayos» o aquel descrito así: «Otro paño tapiz de verduras demediado e sin seda, con un grifo e un león e ciertas aves» ${ }^{11}$.

Propios también del mundo caballeresco son asuntos como el de una antepuerta que tenía enmedio «un mancebo coronado» ${ }^{12}$ o el paño «nuevo con mucha seda, de figuras, e con una serpiente a los pies de un caballero armado» ${ }^{13}$.

Tampoco faltaban los temas mitológicos: «otro paño tapiz nuevo, con mucha seda de figuras de Jasón con el vellocino dorado» ${ }^{14}$, uno con Eolo ${ }^{15}$ y otro que tenía «un rey figurado en lo alto del paño, con un ramo en la una mano derecha y en la otra un cetro y el Dios Cupido a sus pies e de figuras», representación que habrá de ser de Jupíter pues, probablemente, el redactor confundiría con un ramo el haz de rayos del dios ${ }^{16}$.

El descrito en vigesimoctavo lugar como «otro paño de tapiz, casi demediado, de figuras $e$ con mucha seda y en él dos caballos blancos, encima del uno, una figura de mujer, e a los pies una mula» podría pertenecer al género de las moralidades y parece sugerir similitudes con paños de series conocidas como «Los Honores», «Las Moralidades» y «Los Pecados Capitales» de la Colección de la Corona de España ${ }^{17}$.

Los contenidos de otros paños son todavía más problemáticos de reconstruir como el de aquel con «unas figuras e unos órganos», ¿quizás una escena cortesana? Y, fruto de un tiempo de aventura y descubrimientos, había una «antepuerta de figuras, y en ella una nao con un estandarte colorado» ${ }^{18}$.

Tema recurrente en el tapiz ha sido el de la Guerra de Troya y, con este asunto, se pintaron los muros de una capilla del Convento de Tezcatepec, seguramente cuando era una casa agustina. De él sólo conozco lo publicado por F. de la Maza (La Mitología Clásica en el arte Colonial de México, 1968), quien sugiere pudo pintarse hacia 1669, pero por su técnica y estilo, más parece una pinceladura del siglo XVI.

Si el inventario del conquistador de la Nueva España es expresivo de la importancia del tapiz, el arte de Aracne ha dejado su impronta en algunas otras tuteladas por deidades diferentes.

La escultura mexicana del siglo xvi, cuando se aplica a la arquitectura, en repetidas ocasiones sugiere conexiones con modelos tapiceros. Dos ejemplos muy claros de ello pueden ser la portada poblana de la «Casa del que mató al animal» y la de Montejo, en Mérida del Yucatán.

Las figuras que adornan las jambas de la primera son francamente anacrónicas puesto que visten a la moda de la corte borgoñona de hacia 1440. Tanto estos criados como los perros que sujetan están envueltos por una maraña de hojas de col, como aquéllas que son frecuentes en los paños del norte de Francia y de Tournai, tejidos desde mediados del siglo xv hasta avanzada la centuria siguiente y que, llamados de «hojas de aristoloquia» acabarán, más tarde, en centros liceros como Audenarde o Enghien, rodeando a caballos o leones, lo cual podemos

\footnotetext{
10 V. Guy De Tervarent: Attributs et symboles dans l'Art Profane 1450-1600, Ginebra, 1958, columnas 153-155.

11 Es el número 22, Gómez de Orozco, op. cit., p. 92.

12 Es el número 16, Gómez de Orozco, op. cit., p. 92

13 Id. id, p. 92, número 25.

14 Id. id., p. 92, número 23.

${ }^{15}$ Id. id., es el citado en el lugar vigesimocuarto.

16 Id. id., p. 92, número 27.

17 G. Delmarcel: «Los Honores», en Reales Sitios, XVI, 1971, nº 62, págs. 41-57 y Paulina Junquera De Vega: Catálogo de Tapices del Patrimonio Nacional, vol. I: siglo XVI, Madrid, 1986, págs. 22-26, 35-44 y 143-159, con abundante bibliografía.

${ }^{18}$ Gómez de Orozco, op. cit., pág. 92, número 14.
} 
también relacionar con algunos de los tapices poseídos por Cortés ${ }^{19}$. Los lebreles que aparecen en las jambas de la Casa poblana se pueden relacionar con los que aparecen en un tapiz tejido en Franconia hacia 1450 y hoy en el Bayerisches Nationalmuseum de Munich ${ }^{20}$.

El escudo que corona la portada yucateca de la Casa de Montejo, con su fondo de menudas hojas, evoca los reposteros tejidos en Flandes en el siglo xv, en los cuales los blasones descansan en praderías llenas de flores, rodeadas por una empalizada en la que se pueden incluir animales heráldicos; y no olvidemos, además, que en la portada emeritense figuran dos salvajes con sus clavas que bien podrían haberse escapado de un tapiz de Tournai.

Pero las decoraciones pétreas de posible origen tapicero no se limitan a ejemplos con representaciones humanas o de animales, sino que hay numerosos casos con motivos repetidos como sucede en los terciopelos labrados o en las sedas adamascadas. Esta decoración textil, repetitiva, es la que algunas veces se ha querido identificar abusivamente con lo mudéjar ${ }^{21}$. Entre ellas podríamos señalar algunas como el arco de la portada de la iglesia de San Francisco Acuauhtla o la portada de la sacristía de Huejotzingo (figura 1). Esta última constituye un testimonio, trasladado a la piedra, de las colgaduras - de tapiz o seda - que adornaban paredes de casas y templos. Podríamos aducir paños tejidos con motivos similares como el repostero que, con las armas de Don Francisco de los Cobos y Molina, el secretario de Carlos I, se debió tejer en Salamanca, ciudad que exportó este tipo de piezas en gran número a las Indias ${ }^{22}$.

Este reflejo textil es aún más evidente en otras artes, en otras técnicas como la pintura mural. Muchas de las grandes decoraciones que llenan los muros de iglesias, dependencias conventuales y algunas de las pocas casas conservadas del siglo xvi, tienen hábitos y ritmos de composición que proceden de los telares.

Los autores de estos murales de pinceladura introdujeron en América no sólo una técnica especialmente apta para la pintura decorativa, sino también una manera barata de sustituir al damasco, al terciopelo y al tapiz tal y como se hacía en la España coetánea, de lo cual es elocuente demostración los falsos tapices pintados de la iglesia de La Magdalena en Medina del Campo $^{23}$ (figura 2).

Estos murales de pincel y al falso fresco, están en el origen de la pintura colonial. En un principio, con esta técnica se pintaron no sólo las escaleras, refectorios y muros de los templos conventuales sino muy posiblemente, los retablos fingidos que antecedieron a los esculpidos y

\footnotetext{
19 ANGULo señaló su relación con la portada del Palacio Municipal de Tlaxcala y recalcó como en «el dintel aparecen granadas, el tema tan empleado por los tejedores góticos, y en las jambas escenas de cacerías, tal vez, como se ha supuesto, inspiradas en tapices». Diego ANGulo IÑIGUEZ: Historia del Arte Hispanoamericano, vol. I, Barcelona, 1945, págs. 461462. George Kubler: Mexican Architecture of the Sixteenth Century, I, pág. 199. Rafael Cómez: Arquitectura y Feudalismo en México, México, 1989, pág. 126-127 niega estas relaciones con el tapiz y apunta como posibles modelos miniaturas de «libros de historia» llegados a la Nueva España en la primera mitad del siglo xvi. Personajes y perros semejantes a los poblanos se observan en los tapices de la serie del Unicornio conservada en el Metropolitan Museum of Art de Nueva York, y concretamente en el paño 6: «La muerte del Unicornio», relacionable, a su vez, con un libro de Horas publicado en París por Thielman Kerver en 1504. Véase: Margaret B. Freeman: The Unicorn Tapestries, Nueva York, 1976, pp. 106-107.

${ }^{20}$ Timothy Husband y Gloria Gilmore-House: The Wild Man Medieval Myth and Symbolism, Nueva York, 1980, The Metropolitan Museum of Art, pág. 84, fig. 46. Los ornamentos vegetales pueden relacionarse con grabados que, a su vez, sirvieron como posible punto de partida para cartones de «verduras» tejidas. Señalemos entre ellos los de Israhel van Meckenem que figuraron en la muestra neoyorquina: «Ornamentos con flores y un salvaje» y «Flore pulchro», números 19 y 37 respectivamente del catálogo.

${ }_{21}$ V. R. CÓmez, op. cit., págs. 124-125.

${ }^{22}$ Los reposteros que, como éste, presentan un blasón sobre un fondo que imita un terciopelo labrado, fueron una especialidad de la manufactura salmantina y han sido confundidos - como en este caso- con obras de Tournai. Véase J.P. AsselBerghs: Tapisseries héraldiques et de la vie quotidienne, Tournai, 1970, $\mathrm{n}^{\circ}$ 9. AsselBerghs lo cree tejido en Tournai pero con las armas añadidas, luego, en España. Dario Boccara: Les belles heures de la tapisserie, Zoug, 1971, págs. 94108. J.J. JUNQUERA, op. cit., 1985, págs. 42-49.

${ }^{23}$ E. García Chico: El arte en Castilla. La Colegiata de Medina del Campo y Otros Estudios, tomo I, Valladolid, 1957, p.p. 31 y 32 y láms. XXII y XXIII. Deben ser obra de Juan Vélez de hacia 1555.
} 


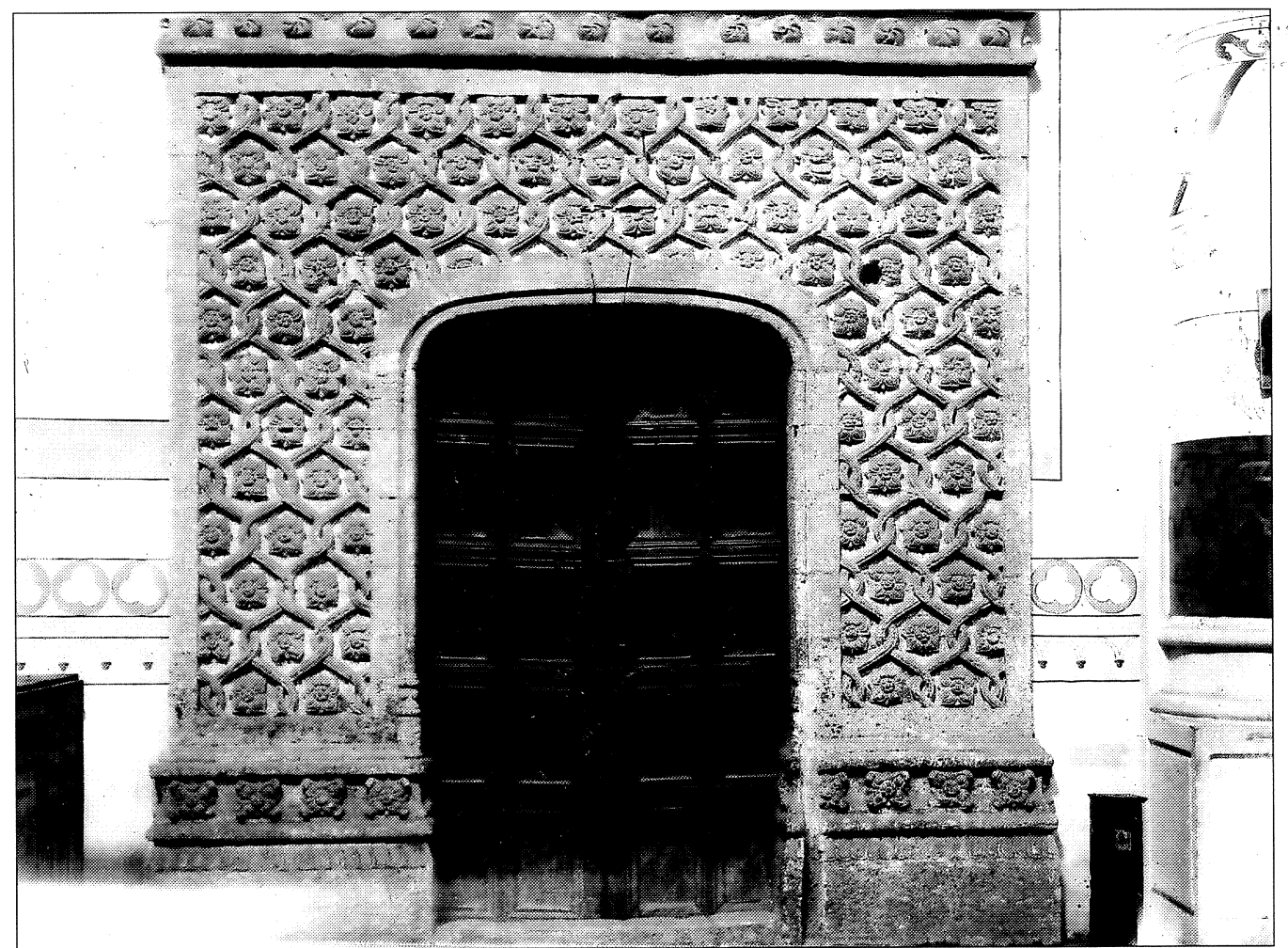

1

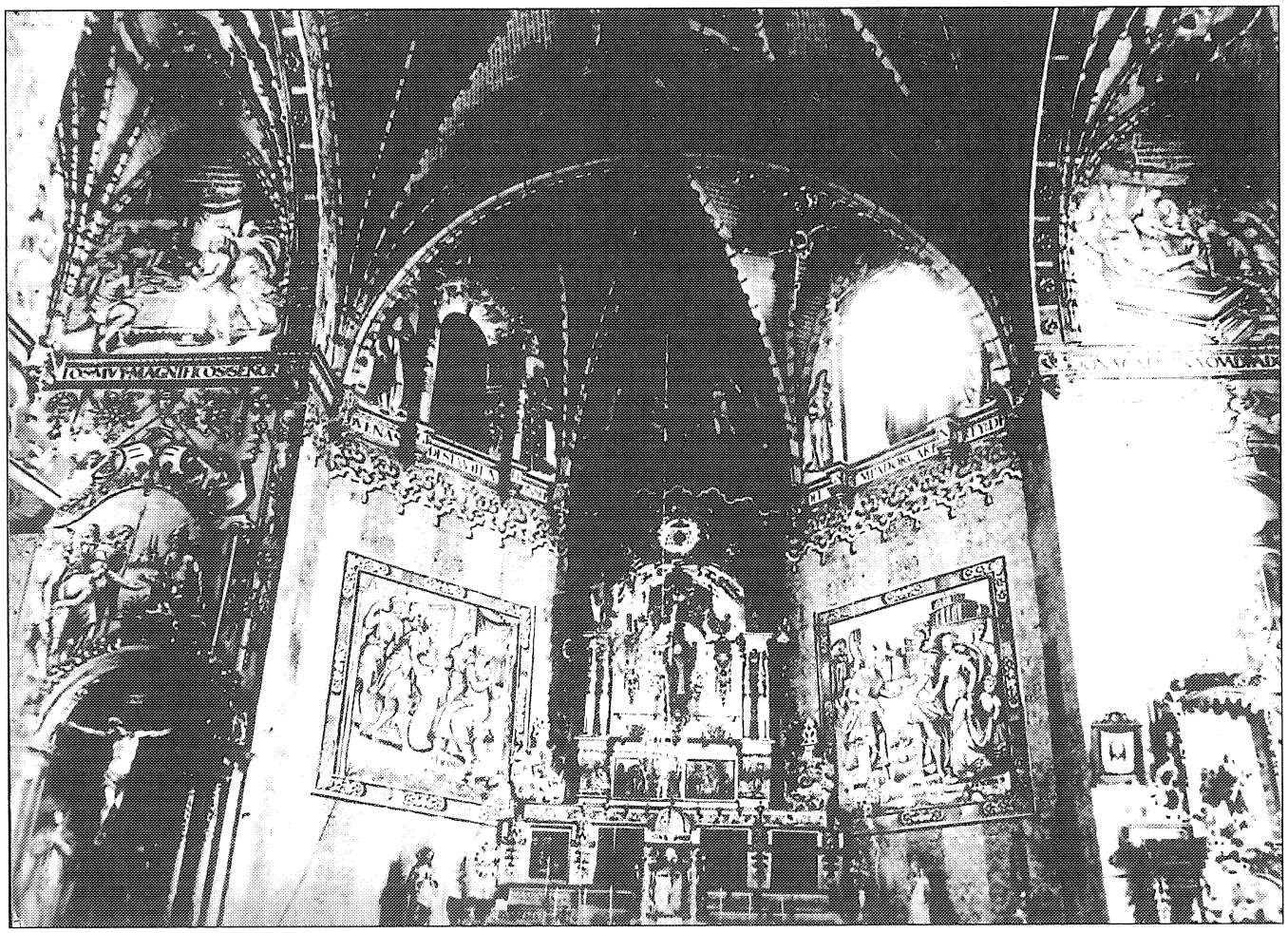

Fig. 1. Portada de la sacristía de Huejotzingo (Puebla).

Fig. 2. Falsos tapices pintados de la iglesia de la Magdalena en Medina del Campo (Valladolid). 
con pinturas de la generación de Pereyns y sus compañeros. Técnica muy común en la España del Siglo xvi, alcanzó una gran popularidad en las provincias vascongadas y no deja de ser sorprendente que, de una zona de España tan ayuna en esa centuria de pintores de interés, parezca que proceden los iniciadores mejicanos. Este debe ser el caso del primer Arrué que llegó a la Nueva España hacia $1549^{24}$ y uno de cuyos nietos casó con la hija de Martín de Zumaya. Entre estos primeros pintores existen unas complejas relaciones familiares pero que, todas, nos conducen a un origen común: la villa quipuzcoana de Zumaya y sus aledaños. Tanto Francisco de Zumaya como Baltasar de Echave de allí procedían y ambos eran parientes a través de las Casas de Zarauz y Gamboa ${ }^{25}$.

Algo parecido sucedería en el Perú, pues pinturas como las de la iglesia de Andahuailillas con Los Dos Caminos del Alma (figura 3) parecen indicarlo. Soria señaló cómo el Camino del Cielo procedía de un grabado de Wierix ${ }^{26}$, pero la arquitectura que en él figura sigue un tipo arquitectónico de casa-fuerte característicamente vascongado y relacionable con el guipuzcoana Palacio de Lili y la Torre de Loyola.

En el Perú, en toda la zona andina, se decoraron las iglesias con murales que, como en Oropesa o Kay-Kay, imitan las colgaduras textiles ${ }^{27}$. En la primera de ellas, en el sotocoro, alternan bandas que reproducen damasco carmesí y un paño de grutescos. En Kay-Kay podemos ver, como en una casulla, bandas «bordadas» entre tiras de damasco así como frisos que posiblemente se copiaron de cenefas de tapices bruselenses y a las que se añadieron encajes de randa flamencos. En Checacupe (figura 4) sobre la fingida colgadura «cuelgan» escenas figuradas que, como los tapices reales, se enmarcan con cenefas y, en Andahuailillas (figura 5), en el coro, unos jarrones bajo unos arcos responden a modelos similares a los que, en el siglo XvII, se tejieron en los tapices llamados «galerías» por su empleo en corredores.

Este tipo de pintura viene, quizás, a continuar la practicada por los antiguos peruanos como aquéllos «cuatro paños de pinturas» que el virrey Don Francisco de Toledo envió a Felipe II en 1572. En ellos, las historias se enmarcaban por unas cenefas lo que, posiblemente, llevó a Toledo a sugerir al rey que, por tales lienzos, se tejieran unos tapices en Flandes para que «con más perpetuidad quedase la verdad que en ellos va» ${ }^{28}$.

En la Nueva España podríamos resaltar los frisos monocromos que, en algunos conventos, reproducen motivos tomados de cenefas de tapiz y uno del Hospital de Jesús de México (figura 6) con la de cascabeles tantas veces empleados por Tournai en sus tapices exóticos como la Historia de Calcú y que, quizás, el pintor viera en los paños con elefantes descritos en el inventario del conquistador ${ }^{29}$ y repetida, en piedra, bajo el escudo de la fachada de la antigua alhóndiga de Puebla (figura 7), sonajas que también se utilizan en los lambrequines de paños heráldicos y se repiten en los pétreos del escudo de la fachada de la antigua Alhóndiga de Puebla, como ya había sido el caso del blasón del Palacio de Dueñas en Mediana del Campo que hubo de conocer Claudio de Arciniega ${ }^{30}$.

También los Triunfos y Sibilas (figuras 8 y 9) que adornan los muros de la Casa del Deán de la Plaza de Puebla, están concebidos como un tapiz con sus campos y cenefas. No debemos

\footnotetext{
24 Toussaint: Pintura colonial en México, México, 1965, p. 71.

${ }^{25}$ Id. Id., p. 72.

${ }^{26}$ De esta cuestión me ocupo en la Historia de la Pintura Colonial que estoy terminando.

27 Pablo Macera: La Pintura Mural Andina. Siglos XVI-XIX, Lima, 1993.

${ }_{28}$ Enrique Marco Dorta: «Las pinturas que envió y trajo a España Don Francisco de Toledo», en Historia y Cultura, $\mathrm{n}^{\circ}$ 9, Revista del Museo Nacional de Historia, Lima, 1977, pág. 69.

${ }^{29}$ J.P. Asselberghs: La tapisserie tournaisienne au XVIe siècle, Tournai, 1968.

${ }^{30}$ F. Lara Arrebola: Artes Textiles en el Palacio de la Casa de Viana en Córdoba, Córdoba, 1982, p. 81, reproduce uno que cree del segundo tercio del s. XVI. Por la forma y colocación del escudo es, sin duda, anterior y, posiblemente de Tournay.
} 


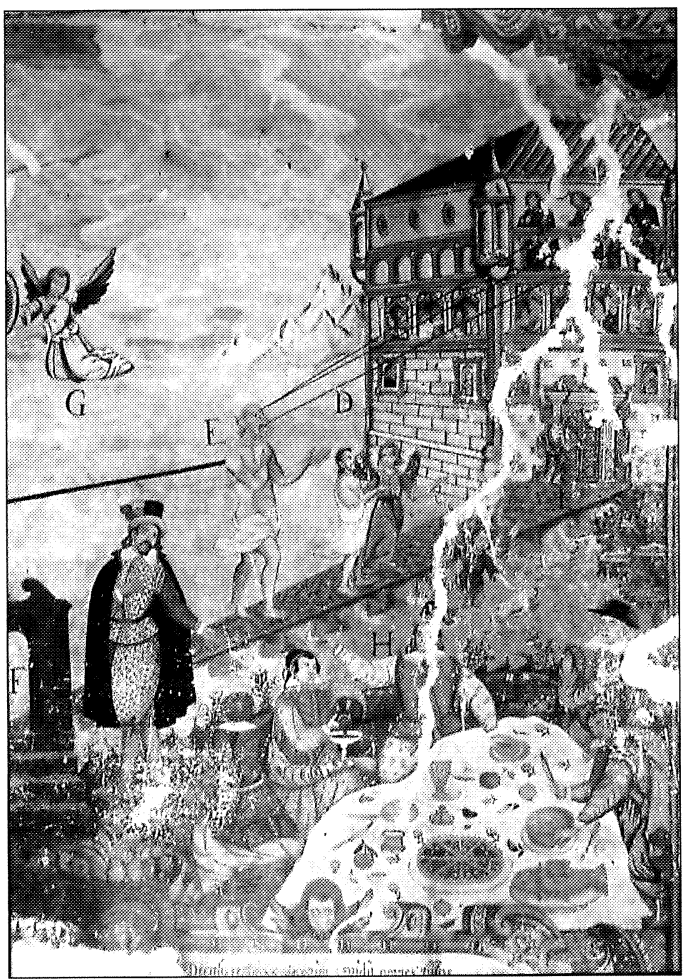

3

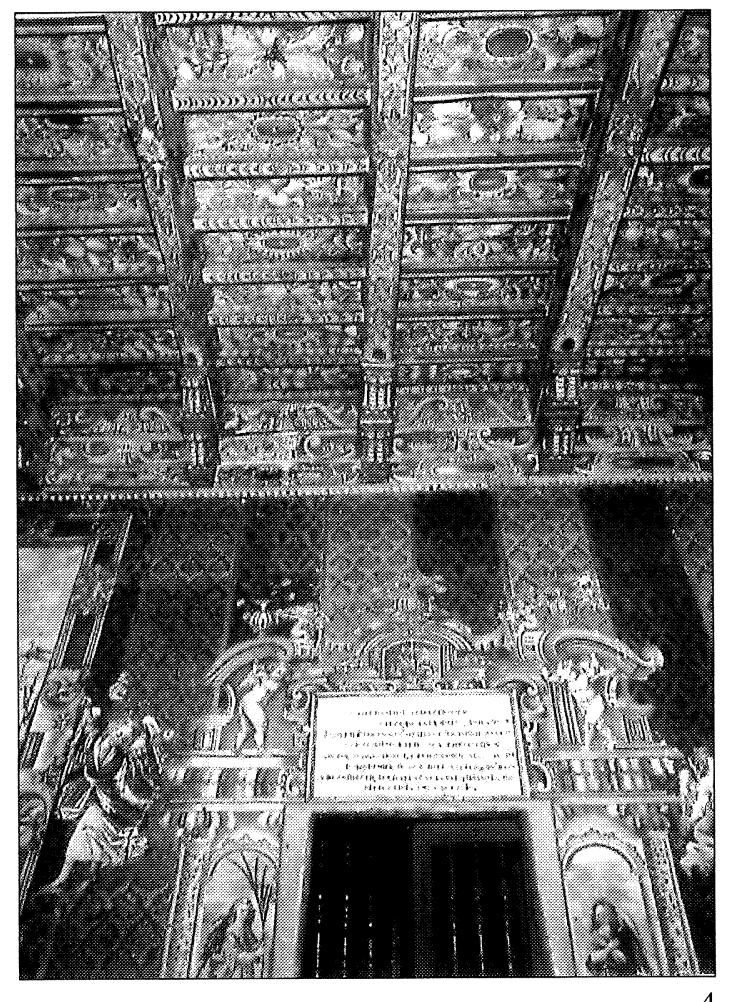

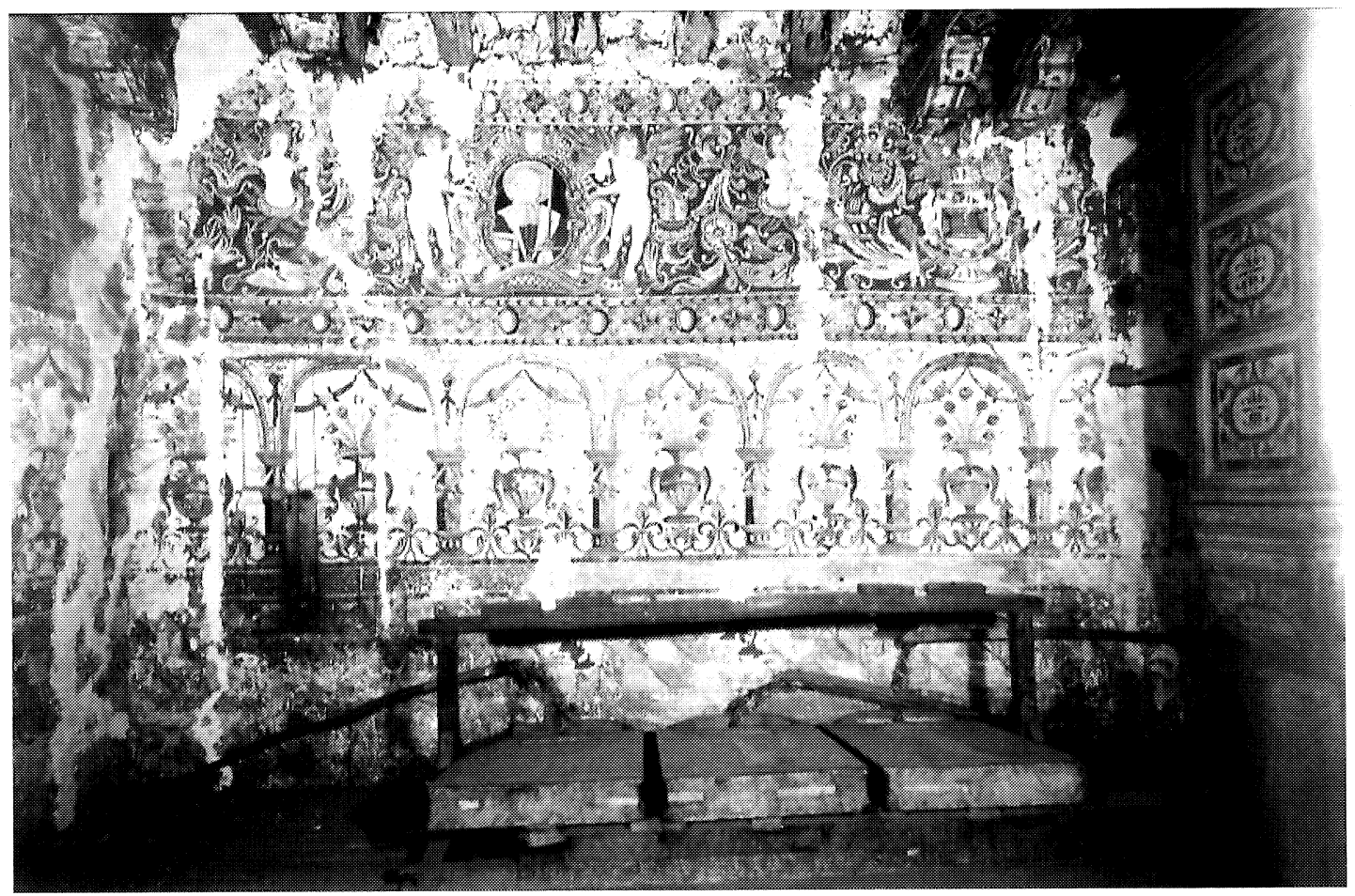

Fig. 3. Pinturas de la iglesia de Andahuailillas (Perú): Los dos Caminos del Alma. Fig. 4. Pinturas en Checacupe (Perú)

Fig. 5. Pinturas del coro de la iglesia de Andahuailillas (Perú). 


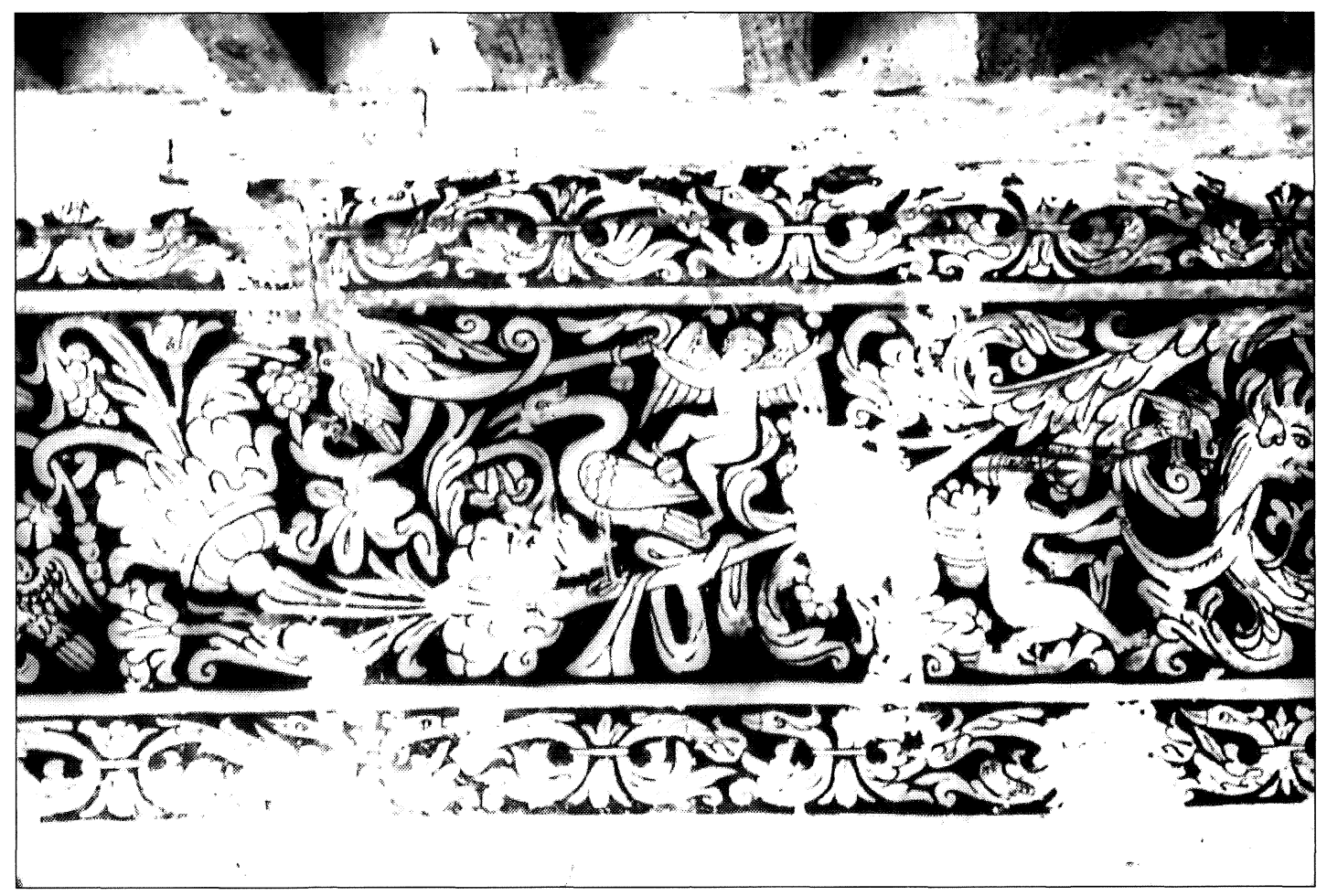

Fig. 6. Pintura al falso fresco del Hospital de Jesús en México (s. xvi).

olvidar que, en 1572, el Colegio de Niñas de México tenía una serie de «seis paños grandes de tapicería de Flandes» con los Triunfos de Petrarca ${ }^{31}$.

Pero es en el convento agustino de Ixmiquilpan donde parece más patente esta relación pintura-tapicería.

Los murales, estudiados por Elena Isabel Estrada de Gerlero ${ }^{32}$, quien señala su diferencia cromática con lo usual en la pintura prehispánica, ofrecen un colorido semejante al de muchas tapicerías del siglo Xvi de relativa calidad, especialmente con aquellas que proceden de centros liceros como Audenarde o Enghien.

Las pinturas que recorren los paramentos de la iglesia son, por su desarrollo, como dos partes de un tapiz: cenefa y campo. La una, sobredimensionada para adquirir igual importancia que lo que sería el segmento principal. Esta «cenefa» que ocupa el lado del Evangelio está

31 E.W. PALM: «El sincretismo emblemático de los Triunfos de la Casa del Deán de la Puebla» en Retablo barroco en memoria de Francisco de la Maza, México, 1974, págs. 11-18. Helga Kropfingen von Kügelgen: «Aspectos iconológicos en los murales de la Casa del Deán en Puebla» en Actes del XIII Congrès International des Américanistes, vol. X, París, 1979, págs. 22-34. SAntiago Sebastián: Iconografía e Iconología del Arte Novohispano, México, 1992, págs. $106-122$. «Los Triunfos» se tejieron numerosas veces en el siglo xvi como lo testimonian las series y paños conservados. Una, completa, de seis paños, se guarda en Viena y, un fragmento del paño del Triunfo de la Muerte sobre la Castidad, según el mismo cartón, en San Francisco. Hay otra, francesa, de tiempos de Luis XII de la cual es versión flamenca una con paños en el Victoria and Albert Museum y Hampton Court. Hay más paños con «Triunfos» en Nueva York (Metropolitan Museum y Hyde Collection, Glen Falls) y en los Musées Royaux D’Art et D’Histoire. Elisabeth Scheicher: Die Trionfi, eine Tapisserienfolge de Kunsthistorischen Museums in Wien, «Jahrbuch der kunsthistorischen Sammlungen i Wien», 31, (1971), p. 27, n. 61. Guy Delmarcel: Text and Image: Some notes on the Tituli of Flemish "Triumphs of Petrarch Tapestries», «Textile History», 20, $\mathrm{n}^{\circ} 2$ (1989). Anna Gray BennetT: Five centuries of Tapestry from the Fine Arts Museums of San Francisco, San Francisco, 1992, pp. 92-95.

32 I. Estrada De Gerlero: «El friso monumental de Itzmiquilpan» en Actes du XIII Congrès des Américanistes, vol. X., París, 1979, págs. 9-19. Véase también: Wigberto Jiménez Moreno: Estudios de Historia Colonial, México, 1958; Abelardo Carrillo y Gabriel: Ixmiquilpan, México, 1961. 


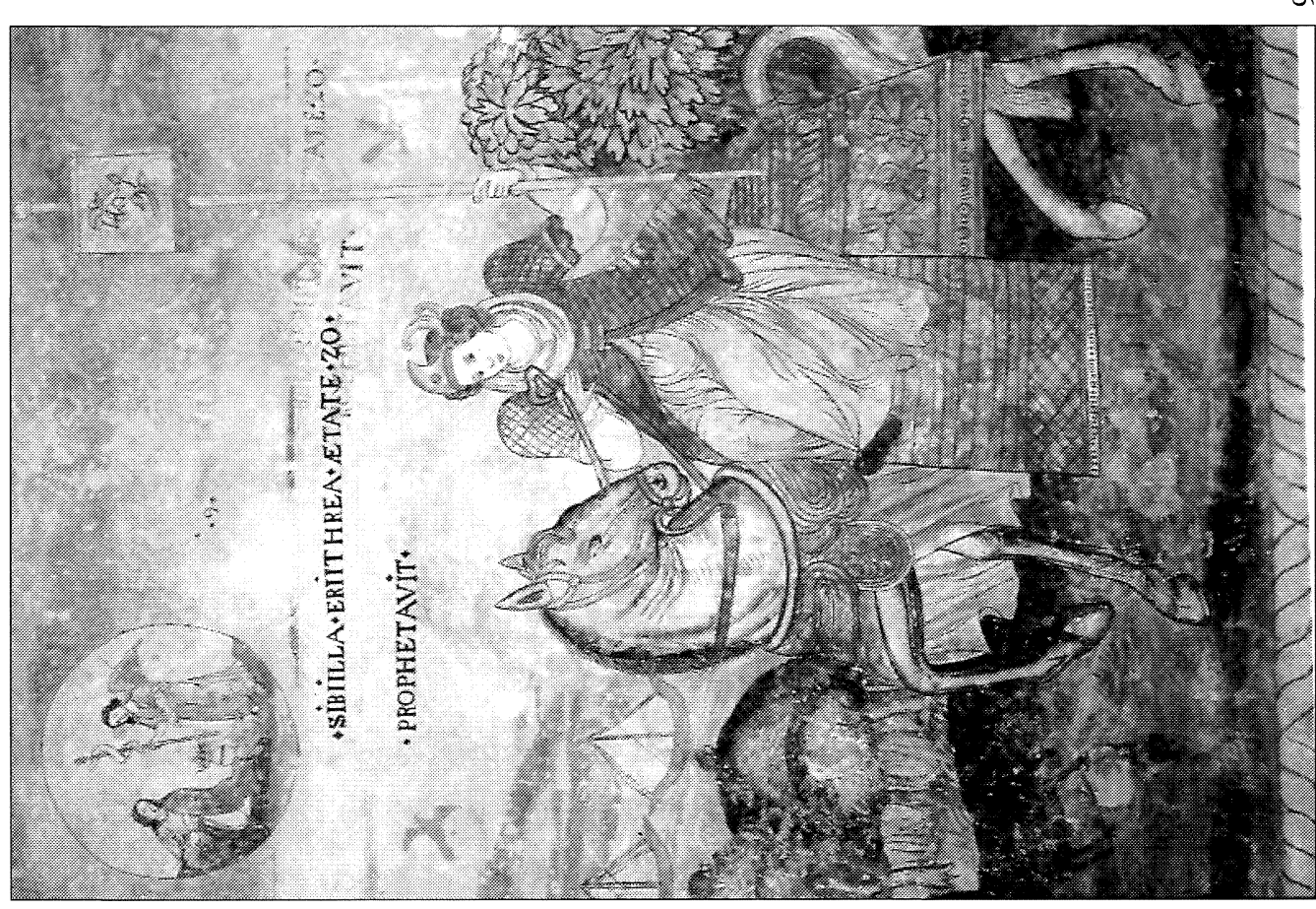

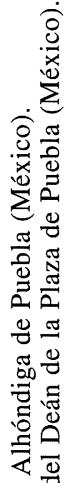
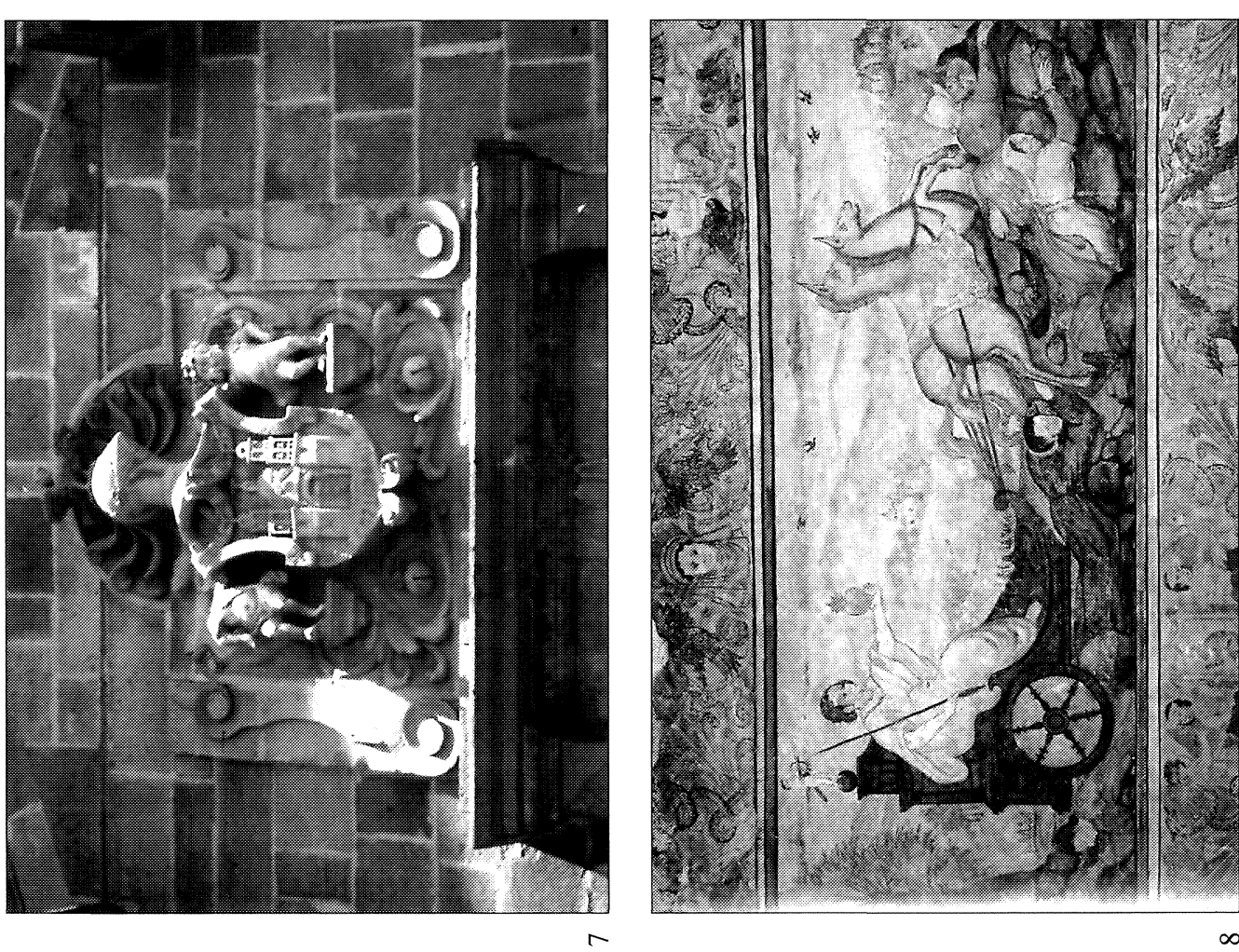

骂

즈 흥

웜

홍

冚词

皮

जै

0.

율

可

$\therefore \infty$

架. 
constituida por unos grutescos que enmarcan un medallón central mientras la pared opuesta aparece decorada por una peculiar psicomaquia. En ella grifos y centauros, guerreros y caballeros-tigre, luchan entre hojarascas a la manera que los «salvajes» lo habían hecho en las tapicerías de Tournai hacia 1500 .

Copia inmediata de grabados o evocación de un tapiz, los frisos de Ixmiquilpan nos traen, de nuevo, el reflejo del mundo caballeresco en el que, esta vez, los paladines son indígenas y sus armas no ya la lanza o la ballesta sino las macanas.

También son indios con rodela y macana, los «salvajes» que aparecen en la puerta de los pies de la Catedral de Ávila, transformada en 1779 y que Azcárate atribuyó a algún colaborador de Juan Guas ${ }^{33}$.

El espejo, al fin, empieza a reflejar un mundo nuevo donde la realidad se funde con la fantasía, lo soñado con lo que se encontró, como había sucedido en la apreciación caballeresca del conquistador.

JuAn JosÉ JunQueRA Y MATO Universidad Complutense

\section{EL RETRATO DE D. CARLOS POR SOFONISBA ANGUISSOLA}

Ha aparecido en una colección madrileña un magnífico ejemplar del famoso retrato de D. Carlos de Sofonisba Anguissola (fig. 1) ${ }^{1}$ que, según la familia propietaria, fue un regalo de palacio.

Sofonisba Anguissola pintó su retrato del Príncipe a petición suya y le gustó tanto al Infante que le encargó al pintor de cámara, Alonso Sánchez Coello ${ }^{2}$ ni más ni menos que 19 copias para repartirlas entre servidores y familia.

Uno de los cronistas más fidedignos de la pintora, el clérigo Pietro Paolo de Ribera, describe el retrato - todavía en vida de Sofonisba- en su obra Le glorie immortali de Trionfi et Heoriche Imprese di Ottocento Quarantacinque Donne Illustre antiche e moderne dotate di conditioni e scienze segnalate, editada en 1609:

«... il Principe Carlo, figlio del Re, volle altresi essere da lei ritratto in piede, al naturale, il quale fece cotanto simille e pieno del magistero dell'arte, vestito d'una fodera di lupo pelle ceruiero e altri ornamenti vaghi sopramodo che rendeva meraviglia. A cui diede quel liberalissimo Prencipe un Diamante di quattro facci di valor di scudi millecinquecento» ${ }^{3}$.

Esta suma, que equivalía más o menos a la misma de ducados, excedía exorbitantemente al precio normal de un retrato de tamaño trescuarto de Sánchez Coello, que se solía fijar entre 30 y 35 ducados. El Príncipe había quedado tan entusiasmado con este retrato — bálsamo para

\footnotetext{
33 J. M. De Azcárate: La arquitectura gótica tolenada del siglo xVI, Madrid, 1958, p. 18.

1 Véase M. KuschE, «Sofonisba e il ritratto di rappresentanza ufficiale nella corte spagnola» en el catálogo de la Exposición Sofonisba Anguissola e le sue sorelle, Cremona, 1994, pp. 131-134.

${ }^{2}$ G. Betz, Die Bildnisse des Don Carlos, Francfort, 1997, pp. 71-94, pp. 293-307 contiene una descripción minuciosa de todas las copias existentes.

3 Ribera 1609, p. 315.
} 